\title{
Oxygen Uptake, Carbon Dioxide Production, Minute Ventilation and Heart Rate during Post Exercise Recovery in Healthy and Unmedicated Elderly and Young Men
}

\author{
Paulo Farinatti, ${ }^{1,2}$, Felipe A Cunha ${ }^{1,3}$, Walace Monteiro ${ }^{1,2}$, Nadia L Silva ${ }^{1}$ and Gabriela Venturini ${ }^{1}$ \\ ${ }^{1}$ Institute of Physical Education and Sports, University of Rio de Janeiro State (UERJ), Brazil \\ ${ }^{2}$ Graduate Program in Sciences of Physical Activity, Salgado de Oliveira University (UNIVERSO), Brazil \\ ${ }^{3}$ Graduate Program in Sciences of Rehabilitation, Augusto Motta University Center (UNISUAM), Brazil

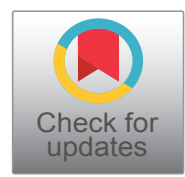 \\ *Corresponding author: Paulo TV Farinatti, PhD, Laboratory of Physical Activity and Health Promotion, Institute of Phys- \\ ical Education and Sports, University of Rio de Janeiro State, Rua Sao Francisco Xavier 524, sala 8121F, Maracana, Rio de \\ Janeiro, CEP 20550-900, Brazil, Tel: +55-21-23340775, E-mail: pfarinatti@gmail.com; paulofarinatti@labsau.org
}

\begin{abstract}
This study investigated the influence of aging and effort intensity upon oxygen uptake $\left(\dot{\mathrm{VO}}_{2}\right)$, carbon-dioxide production $\left(\dot{\mathrm{V} C O}_{2}\right)$, minute ventilation $\left(\dot{\mathrm{V}}_{\mathrm{E}}\right)$ and Heart Rate $(\mathrm{HR})$ during postexercise recovery. Young (YG: $n=16 ; 24 \pm 2 \mathrm{yr}$ ) and older (OG: $n=18 ; 63 \pm 1$ yr) groups performed cycle ergometer exercise bouts at $100 \%, 75 \%$, and $40 \%$ of maximal work rate, preceded by 30 -min resting assessment. Postexercise data were acquired during 15-min passive recovery. In all cases, postexercise recovery was best described by two vs. single exponential equation $\left({ }_{0}^{\infty} x(t) d t=A / \alpha+B / \beta\right)$, $A / \alpha$ and $B / \beta$ constants designating fast and slow components, respectively. On average, the relative contribution of $\mathrm{A} / \alpha$ was similar $(\mathrm{P}>0.05)$ across age groups and work rates (YG vs. OG: $\dot{\mathrm{V} O} \mathrm{O}_{2}-42 \%$ vs. $45 \%$; $\dot{\mathrm{VCO}}_{2}-38 \%$ vs. $39 \%$; $\dot{\mathrm{V}}_{\mathrm{E}}-$ $26 \%$ vs. $27 \%$; HR - $15 \%$ vs. $16 \%$ ). The relative contribution of $B / \beta$ was also similar between age groups $(P>0.05)$ and increased with exercise intensity $(\mathrm{P}<0.05)$ for $\dot{\mathrm{VO}}_{2}$ (YG vs. OG: Ex $100 \%$ - $69 \%$ vs. $69 \%$; Ex75\% - 56\% vs. $50 \%$; Ex40\% - 48\% vs. 47\%) and HR (YG vs. OG: Ex100\% - 93\% vs. $92 \%$; Ex40\% - 69\% vs. $63 \%$ ), but not $\dot{\mathrm{VCO}}_{2}$ and $\dot{\mathrm{V}}_{\mathrm{E}}$. Total recovery was similar in $O G$ and $Y G$ for all variables $(P>$ 0.05). However, recovery curves of $\dot{\mathrm{VCO}}_{2}, \dot{\mathrm{V}}_{\mathrm{E}}$ and HR lasted longer in $O G$ than $Y G(P<0.05)$. In conclusion, aging did not affect total postexercise recovery or relative contribution of fast or slow components. Exercise intensity but not age prolonged $\dot{\mathrm{VO}}_{2}$ recovery, while slow components of $\dot{\mathrm{V}}_{2}$ and $\dot{\mathrm{V}}_{\mathrm{E}}$ were longer in OG. HR recovery increased with age and was markedly longer than respiratory variables, particularly among older individuals.
\end{abstract}

\author{
Keywords \\ Cardiopulmonary exercise testing, Aging, Aerobic exercise, \\ EPOC, Exercise physiology
}

\section{Introduction}

Cardiorespiratory responses during exercise have been extensively described in populations with different demographic and clinical characteristics [1-5], while fewer studies focused on postexercise recovery [6]. However, more recently this "window", defined as the time between the end of a bout of exercise and the subsequent return to what is considered a "resting" state, has been considered as a discrete phenomenon that should be given attention as an independent and valuable source of information. Indeed, the analysis of recovery from exercise may provide insights that could help optimize practical applications in terms of exercise recommendations for health and performance [7]. For instance, aerobic training prescription and control are sometimes based upon the relationship between exercise intensity and recovery duration [8], particularly within athletic fatigue/performance [9]. Furthermore, postexercise adjustments relate with homeostatic ability and health [7].

Undoubtedly, the most studied variable during postexercise recovery is the oxygen uptake $\left(\dot{\mathrm{V}}_{2}\right)$

Citation: Farinatti P, Cunha FA, Monteiro W, Silva NL, Venturini G (2018) Oxygen Uptake, Carbon Dioxide Production, Minute Ventilation and Heart Rate during Post Exercise Recovery in Healthy and Unmedicated Elderly and Young Men. Int J Sports Exerc Med 4:095. doi.org/10.23937/2469-5718/1510095 Accepted: July 03, 2018; Published: July 05, 2018

Copyright: (C) 2018 Farinatti P, et al. This is an open-access article distributed under the terms of the Creative Commons Attribution License, which permits unrestricted use, distribution, and reproduction in any medium, provided the original author and source are credited. 
[8,10-13]. In the early 1920s, Hill, et al. [14,15] originally demonstrated that $\dot{\mathrm{V}}_{2}$ recovery from intense exercise involved fast and slow phases. Subsequently, Margaria, et al. [16] and Henry $[17,18]$ proposed that components of $\dot{\mathrm{V}} \mathrm{O}_{2}$ recovery could be described by the sum of two exponential components as in the equation $X(t)=A e$ ${ }^{\alpha t}+\mathrm{Be}^{-\beta t}$. The first component corresponded to aerobic replenishment of ATP and PCr stores and the second reflected lactate recovery [19]. Additional research quantified those components $[20,21]$ and demonstrated that this mathematical model could be also applied to recovery curves of carbon dioxide production $\left(\dot{\mathrm{V}} \mathrm{CO}_{2}\right)$, ventilation minute $\left(\dot{\mathrm{V}}_{\mathrm{E}}\right)$, and heart rate $(\mathrm{HR})[22,23]$.

Research in regard to postexercise recovery has mostly investigated young or middle-age adults [24]. However, to extend these observations to older individuals is important, since aging has long been associated with an attenuation of aerobic capacity and adrenergic stimulation during exercise $[5,25,26]$. For this reason, the effects of aging upon exercise performance have been compared to those of adrenergic blocking administered to young subjects [22,27]. An equivalent impact on the time and/or capacity to bring cardiorespiratory variables to resting levels would be certainly related to lower ability to recover and resume physical work, with obvious consequences to the overall work capacity in the elderly. Furthermore, limitations pertaining physical status and clinical conditions frequently preclude comparisons between healthy older and younger groups. This would be nonetheless useful, since information about expected values may help establishing goals and provide parameters to evaluate the impact of training upon cardiorespiratory markers throughout aging.

One of the few studies examining age-related effects upon respiratory recovery from different exercise intensities demonstrated that older subjects had reduced upward drift of gas exchange variables and HR during continuous submaximal exercise [22]. Overall, the time of $\dot{\mathrm{VO}}_{2}, \mathrm{VCO}$, and $\dot{\mathrm{V}}_{\mathrm{E}}$ to return to resting levels increased with aging. However, those data referred to a relatively small sample of eight participants aged 60-72 yrs., which performed only 10 minutes of constant-load exercise consisting of pedaling at $70 \%$ of maximal work rate. Evidently, this is not enough to establish a universal recovery pattern, considering larger samples and different exercise intensities. A previous study by our group assessed the cardiorespiratory responses following exercise bouts performed at $40 \%, 75 \%$, and $100 \%$ of peak $\dot{\mathrm{V}}_{2}$ in 10 young and 10 older individuals [28]. Data for $\dot{\mathrm{VO}}_{2}, \dot{\mathrm{V}} \mathrm{CO}_{2}, \dot{\mathrm{V}}_{\mathrm{E}}$, and HR exhibited better adjustment to models with two vs. one exponential during 15-min recovery. Moreover, the influence of exercise intensity upon both faster and slower recovery was greater in older than young individuals. However, limitations as the small sample and lack of control of used medications warranted a replication of the protocol, to ratify those preliminary findings.
A better understanding about cardiorespiratory recovery in older vs. young unmedicated individuals would be relevant to provide parameters for exercise prescription and health evaluation in this specific population. Given the lack of data on this matter, the present study compared the $\dot{\mathrm{V}}_{2}, \dot{\mathrm{V}} \mathrm{CO}_{2}, \dot{\mathrm{V}}_{\mathrm{E}}$, and HR during postexercise recovery from aerobic exercise performed with different intensities in healthy and unmedicated older and young men. Due to expected age-related changes in central and peripheral components determining aerobic capacity, we hypothesized that healthy older individuals would have reduced $\dot{\mathrm{V}}_{2}$ drift and slower recovery in comparison with younger individuals with similar clinical status and relative fitness, affecting the kinetics of $\dot{\mathrm{V}} \mathrm{O}_{2}, \dot{\mathrm{V} C \mathrm{C}_{2}}, \dot{\mathrm{V}}_{\mathrm{E}}$, and $\mathrm{HR}$ return to resting levels. However, total recovery was expected to be similar across age groups.

\section{Methods}

\section{Subjects}

After advertisement, thirty-six healthy males volunteered for the study and were assigned into young (YG) ( $n=16$; age $=25 \pm 2$ yrs.; $1.8 \pm 0.5 \mathrm{~m} ; 77 \pm 6 \mathrm{~kg}$ ) and $\operatorname{older}(\mathrm{OG})(\mathrm{n}=20$; age $=64 \pm 1$ yrs.; $1.7 \pm 0.2 \mathrm{~m} ; 71 \pm$ $8 \mathrm{~kg}$ ) groups. Subjects dwelled in community, exhibited normal weight and were moderately active, practicing at least 3 hours per week of light activities, as walking or jogging. Participants were non-smokers and unmedicated for any type of cardiovascular disorder (hypertension, cardiac disease etc). Additional exclusion criteria were blood pressure abnormalities, heart disease, pulmonary limitation, locomotion impairment, or other condition that could preclude exercise performance or influence cardiorespiratory responses during and after exercise. Health information was extracted from patients' medical records with the agreement of their primary physicians. All participants provided informed consent. This experiment is part of a broader project, which gained approval from the institutional ethical committee of the University of Rio de Janeiro State (CAAE 38263114.7.0000.5259).

\section{Procedures}

Participants performed a cycle ergometer maximal Cardiopulmonary Exercise Testing (CPET) designed to elicit individual volitional exhaustion [27]. The test protocol included 3 min warming-up at $5 \mathrm{~W}$, which was followed by incremental exercise beginning at $25 \mathrm{~W}$ with similar work rate being added every min. Test interruption followed recommendations of the American College of Sports Medicine [29]. The CPET was considered as maximal if at least two of the following criteria were observed [30]: Score 10 on Borg CR-10 scale; $90 \%$ predicted $\mathrm{HR}_{\text {max }}$ [220 - age] or heart rate plateau ( $\triangle \mathrm{HR}$ between two consecutive work rates $\leq 4$ beats $\left.\cdot \mathrm{min}^{-1}\right) ; \dot{\mathrm{VO}}{ }_{2}$ plateau $\left(\Delta \dot{\mathrm{V}}_{2}\right.$ between two consecutive work rates $<2.1$ $\left.\mathrm{mL} \cdot \mathrm{kg}^{-1} \cdot \mathrm{min}^{-1}\right)$; respiratory exchange ratio (RER) $>1.10$. 
Table 1: Cardiorespiratory data at rest and maximal exercise in young and older groups $(n=36)$.

\begin{tabular}{|c|c|c|c|c|c|c|c|c|}
\hline \multirow[t]{2}{*}{ Variable } & \multicolumn{4}{|c|}{ Young group $(n=16)$} & \multicolumn{4}{|c|}{ Older group $(n=20)$} \\
\hline & rest & Ex40\% & Ex75\% & Ex100\% & rest & Ex40\% & Ex75\% & Ex100\% \\
\hline$\dot{\mathrm{V}} \mathrm{O}_{2}\left(\mathrm{~mL} \cdot \mathrm{kg}^{-1} \cdot \mathrm{min}^{-1}\right)$ & $4 \pm 1$ & $24 \pm 6+^{+}$ & $38 \pm 4^{\dagger}$ & $53 \pm 6^{\dagger}$ & $4 \pm 0$ & $20 \pm 4^{\dagger}$ & $29 \pm 6^{*}$ & $36 \pm 6^{*}$ \\
\hline$\dot{\mathrm{V}} \mathrm{VO}_{2}\left(\mathrm{mLkg}^{-1} \cdot \mathrm{min}^{-1}\right)$ & $5 \pm 1$ & $32 \pm 4^{+}$ & $48 \pm 6^{+}$ & $62 \pm 8^{+}$ & $5 \pm 0$ & $27 \pm 5^{\dagger}$ & $35 \pm 6^{*}$ & $42 \pm 6^{*}$ \\
\hline$\dot{\mathrm{V}}_{\mathrm{E}}\left(\mathrm{mL} \cdot \mathrm{kg}^{-1} \cdot \mathrm{min}^{-1}\right)$ & $151 \pm 26$ & $728 \pm 86^{\dagger}$ & $1408 \pm 276^{\dagger}$ & $1705 \pm 370^{\dagger}$ & $138 \pm 16$ & $691 \pm 45^{\dagger}$ & $1001 \pm 85^{\star}$ & $1234 \pm 190^{*}$ \\
\hline HR (bpm) & $73 \pm 7$ & $128 \pm 6^{\dagger}$ & $166 \pm 7^{\dagger}$ & $186 \pm 9^{\dagger}$ & $80 \pm 7$ & $132 \pm 7^{\dagger}$ & $151 \pm 5^{\star}$ & $156 \pm 8^{*}$ \\
\hline Work rate (watts) & 0 & $88 \pm 10^{+}$ & $180 \pm 12^{+}$ & $244 \pm 31^{\dagger}$ & 0 & $59 \pm 7^{*}$ & $103 \pm 10^{*}$ & $146 \pm 18^{*}$ \\
\hline
\end{tabular}

": Significantly different than young group $(P<0.05)$; ${ }^{\dagger}$ : Significantly different than previous work rate $(P<0.05)$

Table 2: Mean deviations of recovery curves from mathematical models with one or two exponents $(n=36)$.

\begin{tabular}{|c|c|c|c|c|c|}
\hline \multirow[t]{2}{*}{ Variable } & \multirow[t]{2}{*}{ Exercise intensity } & \multicolumn{2}{|l|}{$x(t)=A e^{-\alpha t}$} & \multicolumn{2}{|c|}{$x(t)=A e^{-\alpha t}+B e^{-\beta}$} \\
\hline & & $Y G(n=16)$ & $O G(n=20)$ & $Y G(n=16)$ & $O G(n=20)$ \\
\hline & $100 \%$ & $D=2.18$ & $D=2.34$ & $D=0.68^{*}$ & $D=0.60^{*}$ \\
\hline \multirow[t]{3}{*}{$\dot{\mathrm{V}} \mathrm{O}_{2}\left(\mathrm{~mL} \cdot \mathrm{kg}^{-1} \cdot \mathrm{min}^{-1}\right)$} & $75 \%$ & $D=1.32$ & $D=1.39$ & $\mathrm{D}=0.57^{\star}$ & $D=0.59^{*}$ \\
\hline & $40 \%$ & $D=0.76$ & $D=0.55$ & $D=0.36^{*}$ & $D=0.43^{*}$ \\
\hline & $100 \%$ & $D=2.49$ & $D=2.87$ & $D=0.74^{\star}$ & $D=0.80^{*}$ \\
\hline \multirow[t]{3}{*}{$\dot{\mathrm{V}} \mathrm{CO}_{2}\left(\mathrm{mLkg}^{-1} \cdot \mathrm{min}^{-1}\right)$} & $75 \%$ & $D=1.10$ & $D=1.30$ & $D=0.46^{\star}$ & $\mathrm{D}=0.77^{\star}$ \\
\hline & $40 \%$ & $D=0.81$ & $D=0.66$ & $D=0.49^{*}$ & $D=0.34^{*}$ \\
\hline & $100 \%$ & $D=101.10$ & $D=95.30$ & $D=19.56^{*}$ & $D=19.11^{*}$ \\
\hline \multirow[t]{3}{*}{$\dot{\mathrm{V}}_{\mathrm{E}}\left(\mathrm{mL} \cdot \mathrm{kg}^{-1} \cdot \mathrm{min}^{-1}\right)$} & $75 \%$ & $D=47.36$ & $D=43.47$ & $D=15.81^{*}$ & $D=21.47^{*}$ \\
\hline & $40 \%$ & $D=26.93$ & $D=25.69$ & $D=13.33^{*}$ & $D=12.13^{*}$ \\
\hline & $100 \%$ & $D=12.30$ & $D=8.23$ & $D=1.98^{*}$ & $D=2.81^{\star}$ \\
\hline \multirow[t]{2}{*}{ HR (bpm) } & $75 \%$ & $D=9.55$ & $D=8.44$ & $D=1.39^{*}$ & $D=1.90^{*}$ \\
\hline & $40 \%$ & $D=3.01$ & $D=3.59$ & $D=1.78^{*}$ & $D=1.85^{\star}$ \\
\hline
\end{tabular}

*: Significantly different vs. single-exponent model.

Subsequently, participants underwent two submaximal exercise bouts with intensity corresponding to $40 \%$ and $75 \%$ of maximal work rate, with durations of $25 \mathrm{~min}$ and $15 \mathrm{~min}$, respectively. Submaximal bouts were interspersed with 48-72 $\mathrm{h}$ intervals, in a random counterbalanced order. In brief, three exercise intensities were compared: Ex100\%, Ex75\%, and Ex40\%. Each exercise bout was preceded by 30 -min baseline assessment to determine $\dot{\mathrm{V}}_{2}, \dot{\mathrm{V}} \mathrm{CO}_{2}, \dot{\mathrm{V}}_{\mathrm{E}}$, and HR at rest. Assessment of 15-min recovery was initiated immediately after the end of exercise bouts (CPET and submaximal bouts) with participants comfortably seated at the lab. A bipolar chest lead (V5) ECG was used to record HR, while ventilatory responses $\left(\dot{\mathrm{V}}_{2}, \dot{\mathrm{V}} \mathrm{CO}_{2}\right.$, and $\left.\dot{\mathrm{V}}_{\mathrm{E}}\right)$ were assessed via metabolic cart (Morgan Scientific ${ }^{\mathrm{TM}}$, Haverhill, MA, USA). Ventilatory responses were averaged and recorded every $30 \mathrm{~s}$. The $30 \mathrm{~s}$ time average provided a good compromise between removing noise from $\mathrm{VO}_{2}$ data while maintaining the underlying trend [31]. In all cases, the ambient temperature ranged within $21-23^{\circ} \mathrm{C}$ and relative humidity within $55-70 \%$.

\section{Statistical analysis}

The Kolmogorov-Smirnov test ratified data normality, and results are expressed as mean \pm standard deviation. Potential differences of cardiorespiratory responses between age groups and exercise intensities were tested by 2-way ANOVA with repeated measures, followed by Fisher LSD post hoc verification in the event of significant $F$ ratios. The recovery pattern of each variable was tested regarding their adjustment to models including one or two exponentials. To determine deviations, the equation $D=\left[\sum_{i} d_{i}^{2} /\left(N_{p}-N_{a}\right)\right]^{1 / 2}$ was used, where $\mathrm{d}_{\mathrm{i}}$ : deviation from the first point, $\mathrm{N}_{\mathrm{p}}$ : number of points; and $\mathrm{N}_{\mathrm{a}}$ : number of adjusted constants. Values of each component of the equation were also determined. Finally, constants for components describing fast and slower recovery from exercise situations were extracted for each variable. Since total recovery of a given variable might be represented by the area under the experimental curve, the integer of two exponential components was individually calculated by the equation $\left[S={ }_{0}^{\infty} x(t)\right.$ $d t=A / \alpha+B / \beta]$. Constants obtained for exercise intensities within age groups were also compared by means of 2-way ANOVA followed by Fisher LSD verification. In all cases, calculations were made using the Statistica 7.0 software (Statsoft ${ }^{\mathrm{TM}}$, Tulsa, OK, USA) and significance level was fixed at $P \leq 0.05$.

\section{Results}

Table 1 presents data obtained at rest and during exercise protocols. None of the young or older subjects showed significant ST segment depression or developed chest discomfort during the CPET or submaximal exercise 
Table 3: Components $A, B, \alpha$, and $\beta$ associated with recovery curves after different exercise intensities $\left(A e^{-\alpha t}+B e^{-\beta t}\right)$.

YOUNG GROUP $(n=16)$

\begin{tabular}{|c|c|c|c|c|}
\hline Intensity & $\dot{\mathrm{VO}}_{2}\left(\mathrm{~mL} \cdot \mathrm{kg}^{-1} \cdot \mathrm{min}^{-1}\right)$ & $\dot{\mathrm{VCO}}_{2}\left(\mathrm{mLkg}^{-1} \cdot \mathrm{min}^{-1}\right)$ & $\dot{\mathrm{V}}_{\mathrm{E}}\left(\mathrm{mL} \cdot \mathrm{kg}^{-1} \cdot \mathrm{min}^{-1}\right)$ & HR (bpm) \\
\hline \multirow[t]{2}{*}{$100 \%$} & $A=44.19 \pm 0.68$ & $A=50.02 \pm 1.27$ & $A=1241.80 \pm 27.26$ & $A=80.00 \pm 1.00$ \\
\hline & $B=3.18 \pm 0.39$ & $B=11.94 \pm 1.23$ & $B=331.54 \pm 18.54$ & $B=29.00 \pm 2.00$ \\
\hline \multirow[t]{2}{*}{$75 \%$} & $A=31.07 \pm 0.71$ & $A=25.30 \pm 1.00$ & $A=709.21 \pm 19.03$ & $A=58.00 \pm 1.00$ \\
\hline & $B=2.52 \pm 0.65$ & $B=7.07 \pm 1.05$ & $B=175.06 \pm 16.94$ & $B=30.00 \pm 2.00$ \\
\hline \multirow[t]{4}{*}{$40 \%$} & $A=18.37 \pm 0.38$ & $A=16.71 \pm 0.59$ & $A=392.12 \pm 14.10$ & $A=33.00 \pm 2.00$ \\
\hline & $B=0.56 \pm 0.19$ & $B=1.73 \pm 0.75$ & $B=24.39 \pm 6.05$ & $B=11.00 \pm 1.00$ \\
\hline & \multicolumn{4}{|c|}{$\alpha\left(\min ^{-1}\right)[1 / \alpha]$} \\
\hline & $\dot{\mathrm{VO}}_{2}\left(\mathrm{~mL} \cdot \mathrm{kg}^{-1} \cdot \mathrm{min}^{-1}\right)$ & $\dot{\mathrm{V} C O}{ }_{2}\left(\mathrm{mLkg}^{-1} \cdot \mathrm{min}^{-1}\right)$ & $\dot{\mathrm{V}}_{\mathrm{E}}\left(\mathrm{mL} \cdot \mathrm{kg}^{-1} \cdot \mathrm{min}^{-1}\right)$ & HR (bpm) \\
\hline $100 \%$ & $1.099 \pm 0.055[0.91]$ & $0.907 \pm 0.043[1.10]$ & $0.888 \pm 0.038[1.13]$ & $0.478 \pm 0.029[2.09]^{*} \varphi$ \\
\hline $75 \%$ & $0.999 \pm 0.045[1.00]$ & $0.998 \pm 0.049[0.95]$ & $1.057 \pm 0.050[0.95]$ & $0.861 \pm 0.043[1.16]$ \\
\hline \multirow[t]{2}{*}{$40 \%$} & $1.044 \pm 0.070[0.96]$ & $1.117 \pm 0.076[0.90]$ & $1.002 \pm 0.067[1.00]$ & $1.543 \pm 0.188[0.65]^{+}$ \\
\hline & \multicolumn{4}{|c|}{$\beta\left(\min ^{-1}\right)[1 / \beta]$} \\
\hline $100 \%$ & $0.036 \pm 0.012[27.78]^{* \varphi}$ & $0.112 \pm 0.035[8.93]^{+}$ & $0.084 \pm 0.001[11.91]^{*+}$ & $0.014 \pm 0.006[71.43]^{*+}$ \\
\hline $75 \%$ & $0.060 \pm 0.024[16.67]^{\varphi}$ & $0.139 \pm 0.019[7.19]^{+}$ & $0.130 \pm 0.012[7.69]^{+}$ & $0.036 \pm 0.002[27.78]^{\varphi+}$ \\
\hline $40 \%$ & $0.052 \pm 0.039[19.23]$ & $0.098 \pm 0.012[10.20]$ & $0.020 \pm 0.027[-]$ & $0.235 \pm 0.074[4.26]$ \\
\hline \multicolumn{5}{|c|}{ OLDER GROUP $(n=20)$} \\
\hline Intensity & $\dot{\mathrm{V}} \mathrm{O}_{2}\left(\mathrm{~mL} \cdot \mathrm{kg}^{-1} \cdot \mathrm{min}^{-1}\right)$ & $\dot{\mathrm{VCO}}_{2}\left(\mathrm{mLkg}^{-1} \cdot \mathrm{min}^{-1}\right)$ & $\dot{\mathrm{V}}_{\mathrm{E}}\left(\mathrm{mL} \cdot \mathrm{kg}^{-1} \cdot \mathrm{min}^{-1}\right)$ & HR (bpm) \\
\hline \multirow[t]{2}{*}{$100 \%$} & $A=48.59 \pm 0.73$ & $A=55.98 \pm 0.70$ & $A=815.15 \pm 21.30$ & $A=60.95 \pm 2.05$ \\
\hline & $B=3.11 \pm 0.51$ & $B=9.90 \pm 0.35$ & $B=243.12 \pm 11.21$ & $B=22.08 \pm 1.10$ \\
\hline \multirow[t]{2}{*}{$75 \%$} & $A=44.53 \pm 0.49$ & $A=31.12 \pm 0.69$ & $A=447.02 \pm 21.60$ & $A=30.01 \pm 1.00$ \\
\hline & $B=2.13 \pm 0.45$ & $B=5.73 \pm 0.31$ & $B=123.10 \pm 19.25$ & $B=14.22 \pm 1.00$ \\
\hline \multirow[t]{4}{*}{$40 \%$} & $A=18.40 \pm 0.41$ & $A=16.94 \pm 0.29$ & $A=309.99 \pm 13.87$ & $A=13.76 \pm 1.00$ \\
\hline & $B=0.88 \pm 0.22$ & $B=3.52 \pm 0.23$ & $B=181.58 \pm 11.09$ & $B=1.19 \pm 0.03$ \\
\hline & \multicolumn{4}{|c|}{$\alpha\left(\min ^{-1}\right)[1 / \alpha]$} \\
\hline & $\dot{\mathrm{VO}}_{2}$ & $\dot{\mathrm{VCO}}_{2}$ & $\dot{\mathrm{V}}_{\mathrm{E}}$ & HR \\
\hline $100 \%$ & $1.030 \pm 0.037[0.97]$ & $0.980 \pm 0.039[0.98]$ & $0.607 \pm 0.020[1.65]^{\varphi}$ & $0.393 \pm 0.020[2.54]^{*}$ \\
\hline $75 \%$ & $1.091 \pm 0.038[0.92]$ & $1.013 \pm 0.062[0.99]$ & $0.738 \pm 0.031[1.36]$ & $0.630 \pm 0.028[1.59]$ \\
\hline \multirow[t]{2}{*}{$40 \%$} & $1.013 \pm 0.059[0.99]$ & $1.099 \pm 0.083[0.91]$ & $0.778 \pm 0.024[1.29]$ & $0.734 \pm 0.011[1.36]$ \\
\hline & \multicolumn{4}{|c|}{$\beta\left(\min ^{-1}\right)[1 / \beta]$} \\
\hline $100 \%$ & $0.032 \pm 0.012[31.25]^{* \varphi}$ & $0.096 \pm 0.014[10.42]^{\varphi}$ & $0.051 \pm 0.026[19.60]^{* \varphi}$ & $0.012 \pm 0.004[83.33]^{*}$ \\
\hline $75 \%$ & $0.050 \pm 0.019[20.00]^{\varphi}$ & $0.101 \pm 0.036[9.90]$ & $0.080 \pm 0.019[12.50]^{\varphi}$ & $0.016 \pm 0.000[62.50]$ \\
\hline $40 \%$ & $0.064 \pm 0.048$ [15.63] & $0.124 \pm 0.027[8.06]$ & $0.126 \pm 0.053[7.94]$ & $0.021 \pm 0.059[-]$ \\
\hline
\end{tabular}

*: Significantly different of Ex75\% $(P<0.05)$; ${ }^{\varphi}$ : Significantly different of Ex40\% $(P<0.05)$; ${ }^{*}$ Significantly different of $O G(P<0.05)$.

bouts. No difference between age groups was detected at rest for any of the observed variables, but cardiorespiratory data during Ex75\% and Ex100\% were always lower in OG than YG $(P<0.05)$. Adjustments calculated for the recovery curves are depicted in Table 2. Deviations were systematically greater when applying models with one vs. two exponents. Therefore, further analyses describing postexercise recovery were performed using the following polynomial equation: $x(t)=A e^{-\alpha t}+B e^{-\beta t}$, where $A$ : value of fast component at time zero; $B$ : value of slow component at time zero; $\alpha$ : recovery rate related to the first exponential; $\beta$ : recovery rate related to the second exponential; e: neperian log basis; t: time.

Table 3 presents components and constants calculated for exercise intensities within age groups. No significant differences between age groups and exercise intensities occurred for the fast component of $\dot{\mathrm{VO}}_{2}$ and $\dot{\mathrm{VCO}}_{2}$. In fact, the duration of this component, as estimated from $1 / \alpha$, was of approximately $1 \mathrm{~min}$ in all experimental situations. The slow component $(\beta)$ of $\dot{\mathrm{V}}_{2}$ recovery was consistently influenced by exercise intensity, but not
$\dot{\mathrm{V} C O}{ }_{2}$. No age-related differences for the slow component of $\mathrm{VO}_{2}$ were detected, despite a tendency of this phase of recovery to be longer among the older individuals. However, after exercise performed with higher intensities, the slow component of $\dot{\mathrm{V}} \mathrm{CO}_{2}$ was significantly longer following Ex100\% and Ex75\% in OG than YG.

Similarly, the fast component of $\dot{V}_{E}$ recovery was not different across age groups. Although the estimated duration of $1 / \alpha$ had also fell around $1 \mathrm{~min}$ in all situations, this constant tended to increase with exercise intensity in OG. Exercise intensity also influenced the slow component of $\dot{V}_{E}$ recovery, which tended to be longer in OG vs. YG. However, due to data dispersion, in YG we could not estimate its duration after Ex40\%. In contrast to respiratory variables, fast and slow components of HR recovery increased with exercise intensity, particularly in YG. Moreover, the duration of slow components of HR were systematically longer in OG than YG. This finding suggests that HR recovery was somewhat dissociated of the return of respiratory variables to resting values, especially among older individuals. Noteworthy, also at 
Table 4: Average total recovery time estimated for fast and slow components $\left(S={ }_{0}{ }^{\infty} x(t) d t\right)=A \alpha+B / \beta$ after different exercise intensities in young and older groups $(n=36)$.

\begin{tabular}{|c|c|c|c|c|}
\hline Young Group $(n=16)$ & Exercise & Fast Component A/ $\alpha$ & Slow Component $B / \beta$ & Total Recovery \\
\hline \multirow[t]{3}{*}{$\dot{\mathrm{V}} \mathrm{O}_{2}\left(\mathrm{mLkg}^{-1} \cdot \mathrm{min}^{-1}\right)$} & $100 \%$ & $41.04(31.29 \%)$ & $90.13(68.71 \%)$ & 131.17 \\
\hline & $75 \%$ & $33.09(43.68 \%)$ & $42.67(56.32 \%)$ & 75.76 \\
\hline & $40 \%$ & $14.10(52.11 \%)$ & $12.96(47.89 \%)$ & 27.06 \\
\hline \multirow[t]{3}{*}{$\dot{\mathrm{V} C O}{ }_{2}\left(\mathrm{mLkg}^{-1} \cdot \mathrm{min}^{-1}\right)$} & $100 \%$ & $56.04(35.36 \%)$ & $102.45(64.64 \%)$ & 158.49 \\
\hline & $75 \%$ & $29.99(40.68 \%)$ & $43.74(59.32 \%)$ & 73.73 \\
\hline & $40 \%$ & $13.65(37.22 \%)$ & $23.02(62.78 \%)$ & 36.67 \\
\hline \multirow[t]{3}{*}{$\dot{\mathrm{V}}_{\mathrm{E}}\left(\mathrm{mL} \cdot \mathrm{kg}^{-1} \cdot \mathrm{min}^{-1}\right)$} & $100 \%$ & $1492.33(26.27 \%)$ & $4189.48(73.74 \%)$ & 5681.81 \\
\hline & $75 \%$ & $679.15(31.16 \%)$ & $1500.19(68.84 \%)$ & 2179.34 \\
\hline & $40 \%$ & $389.17(22.05 \%)$ & $1376.03(77.95 \%)$ & 1765.20 \\
\hline \multirow[t]{3}{*}{ HR (bpm) } & $100 \%$ & $161.02(7.30 \%)$ & $2045.77(92.70 \%)$ & 2206.79 \\
\hline & $75 \%$ & $67.89(7.40 \%)$ & $849.05(92.60 \%)$ & 916.94 \\
\hline & $40 \%$ & $22.03(31.45 \%)$ & $48.02(68.55 \%)$ & 70.05 \\
\hline Older Group $(n=20)$ & Exercise & Fast Component $\mathrm{A} / \alpha$ & Slow Component $B / \beta$ & Total Recovery \\
\hline \multirow[t]{3}{*}{$\dot{\mathrm{VO}}_{2}\left(\mathrm{mLkg}^{-1} \cdot \mathrm{min}^{-1}\right)$} & $100 \%$ & $42.30(31.46 \%)$ & $92.15(68.54 \%)$ & 134.45 \\
\hline & $75 \%$ & $37.93(49.96 \%)$ & $42.85(53.04 \%)$ & 80.78 \\
\hline & $40 \%$ & $16.39(53.44 \%)$ & $14.28(46.56 \%)$ & 30.67 \\
\hline \multirow[t]{3}{*}{$\dot{\mathrm{V} C O}{ }_{2}\left(\mathrm{mLkg}^{-1} \cdot \mathrm{min}^{-1}\right)$} & $100 \%$ & $57.50(36.54 \%)$ & $99.87(63.46 \%)$ & 157.37 \\
\hline & $75 \%$ & $31.11(42.16 \%)$ & $42.68(57.84 \%)$ & 73.79 \\
\hline & $40 \%$ & $15.64(37.44 \%)$ & $26.13(62.56 \%)$ & 41.77 \\
\hline \multirow[t]{3}{*}{$\dot{\mathrm{V}}_{\mathrm{E}}\left(\mathrm{mL} \cdot \mathrm{kg}^{-1} \cdot \mathrm{min}^{-1}\right)$} & $100 \%$ & $1512.10(26.43 \%)$ & 4209.07 (73.57\%) & 5721.17 \\
\hline & $75 \%$ & $697.41(31.55 \%)$ & $1513.00(68.45 \%)$ & 2210.41 \\
\hline & $40 \%$ & $396.09(22.18 \%)$ & $1389.40(77.82 \%)$ & 1785.49 \\
\hline \multirow[t]{3}{*}{ HR (bpm) } & $100 \%$ & $167.42(8.14 \%)$ & $1889.43(91.86 \%)$ & 2056.85 \\
\hline & $75 \%$ & $70.55(7.46 \%)$ & $874.92(92.54 \%)$ & 945.47 \\
\hline & $40 \%$ & $22.56(31.47 \%)$ & $49.12(68.53 \%)$ & 71.68 \\
\hline
\end{tabular}

Ex40\% the high dispersion of $1 / \beta$ precluded the estimation of this component of HR recovery in OG.

Table 4 depicts data of areas under the recovery curves, which produced an estimation of total recovery and relative contribution of fast $(A / \alpha)$ and slow $(B / \beta)$ components in each exercise situation. As expected, total recovery increased with exercise intensity. However, there was no difference between YG and OG for the total recovery of any variable within the different exercise bouts. The relative contribution of slow components for the total recovery of $\dot{\mathrm{VO}}_{2}$, but not $\dot{\mathrm{VCO}}_{2}$ and $\dot{\mathrm{V}}_{\mathrm{E}}$, seemed to increase with exercise intensity, irrespective of the age group. In regard to HR, in both age groups the slow component accounted for almost all recovery after Ex100\% and Ex75\% ( 90\%). However, after Ex40\% the relative contribution of recovery components to HR normalization was closer to that observed for the respiratory variables (30\% vs. $70 \%$, respectively).

\section{Discussion}

The present study described and compared cardiorespiratory recovery curves after different exercise intensities, in healthy and unmedicated young and older individuals. As expected, irrespective of age the recovery curves for $\dot{\mathrm{VO}}_{2}, \dot{\mathrm{V}} \mathrm{CO}_{2}, \dot{\mathrm{V}}_{\mathrm{E}}$ and $\mathrm{HR}$ were better described by a model including two exponents rather than one (fast and slow components, respectively). Age seemed not to be a major determinant of $\dot{\mathrm{VO}}_{2}$ and $\dot{\mathrm{V}} \mathrm{CO}_{2}$ recovery, and exercise intensity influenced the slow, but not the fast component. The fast component lasted approximately 1 min for $\dot{\mathrm{V}}_{2}, \dot{\mathrm{V}} \mathrm{CO}_{2}$, and $\dot{\mathrm{V}}_{\mathrm{E}}$, regardless the age group or exercise intensity. Both fast and slow components of $\dot{\mathrm{V}}_{\mathrm{E}}$ recovery were longer in OG than YG, but total ventilation was quite similar across the age groups, which is suggestive of a less efficient respiratory buffering system in older than young group. In contrast, fast and slow components of HR recovery were always longer among the older individuals, significantly increasing with exercise intensity. Incidentally, postexercise recovery was longer for HR than any other variable, particularly in OG.

As mentioned above, fast components of $\dot{\mathrm{VO}}_{2}$ and $\dot{\mathrm{VCO}}_{2}$ recovery lasted approximately $1 \mathrm{~min}$ and were similar between exercise intensities and age groups (Table 2 and Table 3). It is therefore feasible to think that a common constant for this component exists, which would be independent of exercise intensity or aging. On the other hand, the slow component of $\mathrm{V}_{2}$ recovery systematically increased with exercise intensity (Table 3). Interestingly, this was not observed for $\dot{\mathrm{V}} \mathrm{CO}_{2}$, particularly in YG. These data suggest that exercise intensity might influence the relative contribution of slow recovery to reestablish resting gas exchange values and that this would be more evident for $\dot{\mathrm{VO}}_{2}$ than $\dot{\mathrm{VCO}}_{2}$. 
In fact, there is a growing body of evidence showing that $\dot{\mathrm{V}} \mathrm{O}_{2}$ recovery, for example, increases exponentially as a function of exercise intensity, whereas linearly as a function of exercise duration [see [32] for a review]. Hagberg, et al. [33] investigated the effects of exercise intensity and duration on the time course and magnitude of VO recovery following short ( $5 \mathrm{~min}$ ) and prolonged $(20 \mathrm{~min}$ ) bouts of cycling at $50 \%, 65 \%$ and $80 \%$ $\dot{\mathrm{V}} \mathrm{O}_{2 \text { peak }}$ in eighteen healthy men (aged 20-33 yr). The magnitude of the fast component of $\dot{\mathrm{VO}}_{2}$ recovery relied on the exercise intensity, irrespective of its duration (5 vs. $20 \mathrm{~min}$ ). In which concerned the slow component of $\dot{\mathrm{V}}_{2}$ recovery, either duration or intensity of exercise bouts have not affected the magnitude of those responses at $50 \%$ or $65 \% \dot{\mathrm{V}} \mathrm{O}_{2 \text { peak }}$. However, at $80 \% \dot{\mathrm{V}} \mathrm{O}_{2 \text { peak }}$ the magnitude of the slow component of $\dot{\mathrm{VO}}_{2}$ recovery was nearly 5 times greater $(P<0.01)$ after the $20 \mathrm{~min}$ vs. 5 min exercise bout. In other words, the time course of the slow component of $\dot{\mathrm{VO}}_{2}$ recovery seemed to increase in exercise bouts with higher intensities $(\geq 65 \%$ $\dot{\mathrm{V}} \mathrm{O}_{2 \text { peak }}$ ) and longer durations (i.e. $\geq 20 \mathrm{~min}$ ).

Our data partially agree with these findings [33]; for example, the fast component $(A / \alpha)$ was indeed similar across all exercise intensities and age groups, but the slow component $(B / \beta)$ was significantly longer after exercise performed with higher intensities (Table 3). Thus, age seemed to be a secondary factor to determine this phase of $\dot{\mathrm{V}}_{2}$ recovery. This finding contradicts the premise that there would be an age-related effect upon the slow component of recovery, as previously suggested [22]. Although aerobic power declines with aging [5] our data suggest that the contribution of the different components of total recovery would be proportional to the relative exercise intensity, and not to maximal cardiorespiratory capacity. Noteworthy, these findings also disagree with a prior study by our group, suggesting that the influence of exercise intensity upon the slow component of $\dot{\mathrm{VO}}_{2}$ and $\dot{\mathrm{VCO}}_{2}$ recoveries would be greater in older than young individuals [28].

In the present study, total $\mathrm{CO}_{2}$ production was similar in OG and YG at all given exercise intensities, as well the relative contribution of both components for the overall recovery (Table 4). However, the slow component was longer in OG than YG at Ex100\% and Ex75\%, suggesting a less effective $\mathrm{CO}_{2}$ buffering in comparison with YG (Table 3). Concisely, elderly and young adults seem to produce similar amounts of $\mathrm{CO}_{2}$ during equivalent exercise. Nevertheless, older individuals probably need more time to bring $\dot{\mathrm{V}} \mathrm{CO}_{2}$ to resting levels. These observations corroborate findings of a prior research [34], claiming that $\dot{\mathrm{V}} \mathrm{CO}_{2}$ recovery would be longer in older than young adults. However, this same study suggested that $\dot{\mathrm{V}} \mathrm{CO}_{2}$ recovery curve would be closely related to $\dot{V}_{\mathrm{E}}$ - this premise has been not confirmed by our data, since the kinetics of $\dot{\mathrm{VCO}}_{2}$ recovery appeared to be shorter and somewhat dissociated of $\dot{V}_{E}$. In this case, it could be argued that $\mathrm{CO}_{2}$ influence upon central re- ceptors might not be the sole determinant of $\dot{V}_{E}$ during post exercise recovery. Alternative pathways could be also implicated, as cortical command or afferent reflex from exercised skeletal muscles [35]. Evidently, additional investigations are warranted to confirm this possibility.

In both age groups, the slow component accounted for most of $\dot{V}_{E}$ recovery (approximately $70-80 \%$ of total) (Table 4). Moreover, exercise intensity seemed to influence both fast and slow components of $\dot{\mathrm{V}}_{\mathrm{E}}$ recovery, at least in OG (Table 3). These findings are consistent with data observed for $\dot{\mathrm{V}} \mathrm{CO}_{2}$. Since $\dot{\mathrm{V} C O}{ }_{2}$ recovery was in OG than YG, $\dot{V}_{E}$ was also expected to remain above resting values for a longer period, which was confirmed by $1 / \beta$ values. Some factors could be at the origin of this difference between age groups, as slower aerobic power, less efficient respiratory buffering, and poorer thermoregulation among the elderly [22]. Another potential explanation for the delayed recovery of gas exchange variables following vigorous exercise among older individuals would be an impaired elimination of $\mathrm{CO}_{2}$ due to reduced $\mathrm{CO}_{2}$ chemosensitivity [36]. It has been shown that the rate of elimination of $\mathrm{CO}_{2}$, after an acute increase in body $\mathrm{CO}_{2}$ stores induced by rebreathing, would relate with the slope of ventilatory responses to $\mathrm{CO}_{2}$, but not with the magnitude of hypercapnia [37]. Therefore, a diminished $\mathrm{CO}_{2}$ chemosensitivity could help to explain age-related delays in $\dot{\mathrm{VO}}_{2}, \dot{\mathrm{V}} \mathrm{CO}_{2}$ and $\dot{\mathrm{V}}_{\mathrm{E}}$ recovery patterns.

Evidences concerning HR recovery are mixed. Williams \& Horvath [6] have proposed that after 30-40 min of moderate exercise, $\dot{\mathrm{V}}_{2}, \dot{\mathrm{V}}_{\mathrm{CO}}$ and $\dot{\mathrm{V}}_{\mathrm{E}}$ would return to resting values within $10 \mathrm{~min}$ of recovery, whereas HR might remain elevated for $30 \mathrm{~min}$. On the contrary, Chick, et al. [22] described respiratory and cardiac responses following exercise performed at $70 \%$ maximal capacity, suggesting that $10 \mathrm{~min}$ of recovery would be enough to normalize $\dot{\mathrm{V}} \mathrm{O}_{2}, \dot{\mathrm{V}} \mathrm{CO}_{2}$ and $\mathrm{HR}$ in a small sample of older individuals. Our findings confirmed the idea that HR and respiratory recovery would somewhat dissociated. Although there was an evident influence of exercise intensity upon HR recovery (similarly to data observed for $\dot{\mathrm{VO}}_{2}, \dot{\mathrm{V}} \mathrm{CO}_{2}$ and $\dot{\mathrm{V}}_{\mathrm{E}}$ ), the slow component of HR recovery was systematically longer vs. all respiratory variables. Moreover, HR recovery was always longer in OG than YG (Table 3). This finding did not agree with our previous study, which suggested that the influence of exercise intensity on HR recovery would be more evident in YG than OG, due to the lower ability of older individuals to increase HR during maximal exercise [28]. On the other hand, there was no difference between age groups for the total HR recovery or relative contribution of fast and slow components (Table 4).

The fact that HR suffered the influence of other factors than solely $\dot{\mathrm{V}}_{2}$, may help explaining its longer recovery in comparison with respiratory variables - for 
instance, differences in lactate metabolism, body temperature, ventilatory rate, or circulating concentrations of catecholamines [38] may also account for a longer recovery $H R$ recovery. This is an important finding for exercise prescription, since overall recovery from exercise bouts is often assessed by means of the return of $\mathrm{HR}$ to preexercise levels. This may correspond to the actual recovery of the respiratory variables in the fast recovery phase (e.g., first $2 \mathrm{~min}$ ), but not during the slow phase, whose duration for HR may be up to three times that observed for respiratory variables, particularly among older individuals.

A potential limitation of the present study was that resting values of $\dot{\mathrm{VO}}_{2}, \dot{\mathrm{V}} \mathrm{CO}_{2}, \dot{\mathrm{V}}_{\mathrm{E}}$ and $\mathrm{HR}$ could not be assessed on a separate day (i.e. non-exercise control day), under identical experimental conditions applied in exercise days. Similar to previous studies, we have defined resting values as the average values of $\dot{\mathrm{VO}}_{2}, \dot{\mathrm{V}}_{\mathrm{CO}_{2}}, \dot{\mathrm{V}}_{\mathrm{E}}$ and HR measured during the last 5 min of a 30-min resting period in a seated position. This strategy was criticized in a systematic review [39], since it can lead to falsely high resting values that compromise the accuracy of recovery rate assessment after exercise. Moreover, the participants were not well matched for their baseline fitness. Our polynomial equations were fit to model few data, which is always problematic. In short, it is difficult to determine linear regressions with, so few participants and the accuracy of recovery curves could be improved with more participants. However, to find older individuals completely unmedicated for cardiovascular features is not a simple task. Although acknowledging the limitation due to the relatively small sample, our findings were consistent enough to establish recovery patterns that probably correspond to the reality, as well as differences between age groups. Finally, the external validity of our findings is restricted to healthy and unmedicated individuals. Although this information is important to address physiological differences between age groups, we must acknowledge that this is frequently not the case of older individuals.

\section{Conclusions}

In conclusion, total recovery of gas exchange variables and HR after exercise bouts performed with similar relative intensity did not differ between young and older healthy and unmedicated individuals, as well as the relative contribution of fast and slow recovery components. Exercise intensity but not age, increased the duration of fast and slow components of $\dot{\mathrm{VO}}_{2}$ recovery. However, the slow components of $\dot{\mathrm{VCO}}_{2}$ and $\dot{\mathrm{V}}_{\mathrm{E}}$ tended to be longer in older than young individuals, perhaps reflecting an age-related reduction in buffering capacity. The duration of HR recovery was longer than respiratory variables, increasing with exercise intensity and age. This is suggestive of dissociation between HR and respiratory recoveries, particularly in older individuals.
In practical terms, total recovery and kinetics of $\dot{\mathrm{VO}}_{2}$, $\dot{\mathrm{V} C \mathrm{CO}_{2}}, \dot{\mathrm{V}}_{\mathrm{E}}$ and $\mathrm{HR}$ were similar across age groups, following exercise bouts of equivalent intensity. However, since the slow component of $\dot{\mathrm{V}} \mathrm{CO}_{2}, \dot{\mathrm{V}}_{\mathrm{E}}$ and $\mathrm{HR}$ were prolonged in older participants, full recovery might take longer in this group, particularly after vigorous exercise. Lastly, HR recovery may not reflect the return of $\dot{\mathrm{V}} \mathrm{O}_{2}, \dot{\mathrm{V}} \mathrm{CO}_{2}$ or $\dot{\mathrm{V}}_{\mathrm{E}}$ to preexercise levels, particularly in older individuals.

\section{Acknowledgements}

This study was partially supported by grants from the 'Carlos Chagas Foundation for the Research Support at the State of Rio de Janeiro' (FAPERJ; E-26/103.126/2011) and the 'Brazilian Council for the Technological and Research Development' (CNPq, process 473551/2013-6). We thank Prof. Jacques H.P. Vanfraechem, PhD, and the Laboratoire de I'Effort of the UniversitéLibre de Bruxelles, for the precious support during data assessment.

\section{Ethical Statement}

This study gained approval from institutional ethics committee (CAAE 38263114.7.0000.5259) and complied with ethical standards laid down in the Declaration of Helsinki. The authors do not have conflicts of interest to declare.

\section{References}

1. Kohrt WM, Malley MT, Coggan AR, Spina RJ, Ogawa T, et al. (1991) Effects of gender, age, and fitness level on response of VO2max to training in 60-71 yr olds. J Appl Physiol (1985) 71: 2004-2011.

2. ASTRAND I (1960) Aerobic work capacity in men and women with special reference to age. Acta Physiol Scand Suppl 49: 1-92.

3. Dehn MM, Bruce RA (1972) Longitudinal variations in maximal oxygen intake with age and activity. J Appl Physiol 33: 805-807.

4. Pollock ML, Mengelkoch LJ, Graves JE, Lowenthal DT, Limacher MC, et al. (1997) Twenty-year follow-up of aerobic power and body composition of older track athletes. J Appl Physiol (1985) 82: 1508-1516.

5. Astrand PO, Bergh U, Kilbom A (1985) 33-yr follow-up of peak oxygen uptake and related variables of former physical education students. J Appl Physiol 82: 1844-1852.

6. Williams RE, Horvath SM (1995) Recovery from dynamic exercise. Am J Physiol 268: 2311-2320.

7. Luttrell MJ, Halliwill JR (2015) Recovery from exercise: vulnerable state, window of opportunity, or crystal ball? Front Physiol 6: 204.

8. Bogdanis GC, Nevill ME, Lakomy HK, Graham CM, Louis $G$ (1996) Effects of active recovery on power output during repeated maximal sprint cycling. Eur J Appl Physiol Occup Physiol 74: 461-469.

9. Bellenger CR, Fuller JT, Thomson RL, Davison K, Robertson EY, et al. (2016) Monitoring Athletic Training Status Through Autonomic Heart Rate Regulation: A Systematic Review and Meta-Analysis. Sports Med 46: 1461-1486.

10. Nummela A, Rusko H (1995) Time course of anaerobic and aerobic energy expenditure during short-term exhaustive 
running in athletes. Int J Sports Med 16: 522-527.

11. Dawson B, Straton S, Randall N (1996) Oxygen consumption during recovery from prolonged submaximal cycling below the anaerobic threshold. J Sports Med Phys Fitness 36: 77-84.

12. Chilibeck PD, Paterson DH, Cunningham DA, Taylor AW, Noble EG (1997) Muscle capillarization O2 diffusion distance, and VO2 kinetics in old and young individuals. J Appl Physiol (1985) 82: 63-69.

13. Short KR, Sedlock DA (1997) Excess postexercise oxygen consumption and recovery rate in trained and untrained subjects. J Appl Physiol (1985) 83: 153-159.

14. Hill AV, Long CNH, Lipton $\mathrm{H}$ (1924) Muscular exercise, lactic acid and the supply and utilization of oxygen. Parts I-III. Proceedings of the Royal Society 96: 438-475.

15. Hill AV, Long CNH, Lupton $\mathrm{H}$ (1925) Muscular exercise, lactic acid and the supply and utilization of oxygen. Parts IV-VI. Proceedings of the Royal Society 97: 84-137.

16. Margaria R, Edwards HT, Dill DB (1933) The possible mechanism of contracting and paying the oxygen debt and the role of lactic acid in muscular contraction. American Journal of Physiology 106: 689-715.

17. Henry FM (1951) Aerobic oxygen consumption and alactic debt in muscular work. J Appl Physiol 3: 427-438.

18. Henry FM, Demoor JC (1956) Lactic and alactic oxygen consumption in moderate exercise of graded intensity. $J$ Appl Physiol 8: 608-614.

19. margaria R, Cerretelli $P$, Diprampero Pe, Massari $C$, Torelli G (1963) Kinetics and mechanism of oxygen debt contraction in man. J Appl Physiol 18: 371-377.

20. Katch VL, Girandola RN, Henry FM (1972) The influence of the estimated oxygen cast of ventilation on oxygen deficity and recovery oxygen intake for moderately heavy bicycle ergometer exercise. Medicine and Science in Sports and Exercise 4: 71-76.

21. Katch VL (1973) Kinetics of oxygen uptake and recovery for supramaximal work of short duration. Int Z Angew Physiol 31: 197-207.

22. Chick TW, Cagle TG, Vegas FA, Poliner JK, Murata GH (1991) The effect of aging on submaximal exercise performance and recovery. J Gerontol 46: 34-38.

23. Joye $H$ (1968) Comparison of the rapid and slow components of the curve of oxygen consumption, of carbonic anhydride elimination and the curve of ventilation during the recovery period. Int $Z$ Angew Physiol 25: 210-223.

24. Osterberg KL, Melby CL (2000) Effect of acute resistance exercise on postexercise oxygen consumption and resting metabolic rate in young women. Int $\mathrm{J}$ Sport Nutr Exerc Metab 10: 71-81.
25. Davy KP, Johnson DG, Seals DR (1995) Cardiovascular, plasma norepinephrine, and thermal adjustments to prolonged exercise in young and older healthy humans. Clin Physiol 15: 169-181.

26. Seals DR, Taylor JA, Ng AV, Esler MD (1994) Exercise and aging: autonomic control of the circulation. Med Sci Sports Exerc 26: 568-576.

27. Farinatti PT, Soares PP (2009) Cardiac output and oxygen uptake relationship during physical effort in men and women over 60 years old. Eur J Appl Physiol 107: 625-631.

28. Farinatti PTV, Vanfraechem JHP, Monteiro WD (1999) Behavior of cardiorespiratory variables in the elderly and young during 15 minutes of recovery after efforts of different intensities. Brazilian Journal of Sports Medicine 5: 212-220.

29. ACSM (2013) ACSM's guidelines for exercise testing and prescription. ( $9^{\text {th }}$ edn), Baltimore: Lippincott Williams \& Wilkins.

30. Howley ET, Bassett DR Jr, Welch HG (1995) Criteria for maximal oxygen uptake: review and commentary. Med Sci Sports Exerc 27: 1292-1301.

31. Midgley AW, McNaughton LR, Carroll S (2007) Effect of the VO2 time-averaging interval on the reproducibility of VO2max in healthy athletic subjects. Clin Physiol Funct Imaging 27: 122-125.

32. LaForgia J, Withers RT, Gore CJ (2006) Effects of exercise intensity and duration on the excess post-exercise oxygen consumption. J Sports Sci 24: 1247-1264.

33. Hagberg JM, Mullin JP, Nagle FJ (1980) Effect of work intensity and duration on recovery O2. J Appl Physiol Respir Environ Exerc Physiol 48: 540-544.

34. Takahashi T, Niizeki K, Miyamoto Y (1997) Respiratory responses to passive and active recovery from exercise. Jpn J Physiol 47: 59-65.

35. Amann M (2012) Significance of Group III and IV muscle afferents for the endurance exercising human. Clin Exp Pharmacol Physiol 39: 831-835.

36. Brischetto MJ, Millman RP, Peterson DD, Silage DA, Pack Al (1984) Effect of aging on ventilatory response to exercise and CO2. J Appl Physiol Respir Environ Exerc Physiol 56: $1143-1150$.

37. Chonan T, Elhefnawy AM, Simonetti OP, Cherniack NS (1988) Rate of elimination of excess CO2 in humans. Respir Physiol 73: 379-394.

38. Bahr R (1992) Excess postexercise oxygen consumption--magnitude, mechanisms and practical implications. Acta Physiol Scand Suppl 605: 1-70.

39. Børsheim E, Bahr R (2003) Effect of exercise intensity, duration and mode on post-exercise oxygen consumption. Sports Med 33: 1037-1060. 